\title{
Finite Element Analysis of High-Strength Concrete Flat Slab with Openings
}

\author{
Aravindan K, Viswanathan T. S. \\ Vellore Institute of Technology, Katpadi - 632014, Tamil Nadu, India \\ Received March 14, 2021; Revised May 6, 2021; Accepted June 6, 2021
}

\section{Cite This Paper in the following Citation Styles}

(a): [1] Aravindan K, Viswanathan T. S. , "Finite Element Analysis of High-Strength Concrete Flat Slab with Openings," Civil Engineering and Architecture, Vol. 9, No. 5, pp. 1572-1581, 2021. DOI: 10.13189/cea.2021.090527.

(b): Aravindan K, Viswanathan T. S. (2021). Finite Element Analysis of High-Strength Concrete Flat Slab with Openings. Civil Engineering and Architecture, 9(5), 1572-1581. DOI: 10.13189/cea.2021.090527.

Copyright $(2021$ by authors, all rights reserved. Authors agree that this article remains permanently open access under the terms of the Creative Commons Attribution License 4.0 International License

\begin{abstract}
Reinforced concrete slabs are an important component of high-rise buildings as they are designed to withstand the loads they are subjected to. Concrete slabs, on the other hand, may fail due to punching shear, which is one of the most serious risks in the slab column connection. This kind of failure, which is difficult to predict, occurs almost instantaneously and can have disastrous consequences. This research aims to examine how high-strength flat slabs act under vertical loads, as well as how openings affect flat slab punching shear strength. To do so, ABAQUS uses a series of non-linear numerical models to simulate the punching shear effect on reinforced concrete flat slabs and to investigate the effects of the various sizes and locations of the openings and the constitutive modeling of concrete on the punching shear stress of the connections. To begin with, the experimental results of Marzouk and Chen were used to perform the initial calibration of the finite element model. The effect of the openings presents in a flat slab with different positions and sizes and distances of $0 \mathrm{~d}, 1 \mathrm{~d}, 2 \mathrm{~d}, 3 \mathrm{~d}, 4 \mathrm{~d}$, and $5 \mathrm{~d}$ far from the column in parallel position was determined by the analysis of 42 internal connections under incremental vertical load, while the connection without opening was used as a reference in each case. The shear strength was reduced by up to 9.6 percent as a result of an opening located at $2 \mathrm{~d}$ distance from the column. This result is unaffected by the number of openings. The experimental and numerical results are also used to evaluate the accuracy of the various code equations available for predicting flat slab punching shear capacity. Eurocode prediction is more accurate than Canadian standard.
\end{abstract}

Keywords Punching Shear Stress, Finite Element
Modeling, Opening, Slab-Column Connections, Flat Slab

\section{Introduction}

The most popular RC structures are reinforced flat concrete slabs supported by columns. There are many benefits, including a simple frame, reduced floor height, and low construction costs. As a result, extensive research has been carried out around the world over the last few decades on the design and construction of flat slabs supported by columns, resulting in the development of design methods, technical specifications, and simple but effective tools. The relationship between the slab and the supporting columns, on the other hand, develops punching shear stress. Punching the shear failure of a single slab-column connection may result in the progressive collapse of a portion of the entire structure due to its brittle nature. The punching shear is a catastrophic type of slab structure failure that occurs without warning when a truncated cone or pyramid-shaped surface around the column is involved. The punching strength of a flat slab-column connection can be increased by the use of a larger column diameter, a thicker slab, a more flexural reinforcement, a higher compressive strength concrete, or using additional shear reinforcement. High-strength concrete has gained popularity in many countries in recent years. Coastal infrastructure, high-rise towers, underwater platforms, and long-distance bridges all use high-strength concrete. High-strength concrete slabs are the main structural characteristics of an offshore concrete structure 
(HSC). The openings are placed in the edge and the internal slab-column connections without the shear reinforcement in normal-strength concrete Moe (Moe, 1961). In the last few decades, only a few researchers (Hussein \& Marzouk, 2000; H. Marzouk et al., 1996, 1999; H. Marzouk \& Hussein, 1991; H. M. Marzouk \& Chen, 1993; Ramdane, 1996) have looked at the relationship between high-strength concrete slabs and columns with and without shear reinforcement. Generally, high-strength concrete slabs are more brittle than normal-strength concrete slabs. Only the conditions of gravity loading are used to measure these slabs. In current researchers, (H. Marzouk \& Hussein, 1991; H. M. Marzouk \& Chen, 1993) tested High-strength interior slab-column connections with specific column and slab compressive strengths and tested under vertical loading by column and equal lateral loading are used to create an unbalanced moment in a column. Following a long period of inactivity, these researchers used high-strength concrete in (Han et al., 2014; Inácio et al., 2020; Smadi \& Bani Yasin, 2008) to predict the punching shear strength of concrete and the behaviour of performance in compressive strength in flat slabs.

The Finite Element Analysis (FEA) in the Modern Method is crucial in complementing experimental research to provide insight into structural behaviour and processes of shear transfer punching in the case discussed here. Use the Nonlinear Finite Element Analysis (NLFEA) model for structural engineers to study the physical behaviour and mechanical behaviour of engineering structures. NLFEA makes research into crack formation and propagation, deflection, complementing experimental results, and potential causes of failure where experimental measurements are not known. The most popular models used in Finite Element Calibrations include: Linear Analysis, Non-Linear Analysis, Continuum Damage Mechanics, and Coupled Damage Mechanics (ABAQUS, 2014; Feenstra \& Borst, 1995; Hillerborg, 1983, 1989; Lee \& Fenves, 1998; Lubliner et al., 1989; Malm, 2006; Mazars, 1986).

This paper focuses on the selection of high-strength slab post-cracking behaviour through the nonlinear finite element analysis (NLFEA) model of tension-stiffening and shear degradation using concrete damage plasticity. Specimen No. 17 of the high strength slab (HS17) (H. M. Marzouk \& Chen, 1993) was considered a reference specimen for the numerical model in the analysis presented herein. The most ground-breaking aspects of this investigation are the detailed description of the constitutive model, including the impact of the material parameters and the predictability of a concrete damaged plasticity model for assessment. The findings of NLFEA contrast with the detailed experimental results of HS17 for Ultimate Load and Ultimate Deflection and the predictive potential of the integrated finite element model. Parametric analysis was a study of the size and location of the column openings. Finally, the results of the NLFEA were compared with design codes such as EC2 and CSA A23.3-04 for flat slab shear resistance punching.

\section{Experimental Background Description}

Seventeen Interior slab-column connections (HS1 to HS17) were tested and analyzed using real-scale models of high-strength slab-column connections (H. Marzouk \& Hussein, 1991; H. M. Marzouk \& Chen, 1993). These high-strength flat slabs had previously been tested with a gravity load (V) applied to the top surface of the column in (H.M. Marzouk 1993). The tensile reinforcement was positioned parallel and perpendicular to the free edge at the bottom of the slab, while the compressive reinforcement was positioned at the top in both directions. With a width-to-thickness ratio of 10 to 17 percent, the reinforcement ratio ranged from 0.49 to 2.37 percent. Hot-rolled bars of 10 -and $15-\mathrm{mm}$ diameter serve as flexural reinforcement (CSA-G30.12 Grade 400) of size $10 \mathrm{~mm}$ and $15 \mathrm{~mm}$ at the top and bottom respectively, with the yield strength 496 and $420 \mathrm{MPa}$. The concrete's compressive strength ranged from 66 to $80 \mathrm{MPa}$. Four bars No. $10 \mathrm{M}$ were placed in the compression zone based on structural integrity criteria. It is worth noting that the slab was designed without any shear reinforcement. Columns with No. 6 simple bars have been over-reinforced as ties to avoid premature failure. The Size of the specimen was $1950 \mathrm{~mm}$ square and simply supported, provided in $1830 \mathrm{~mm} \times 1830 \mathrm{~mm} \times 150 \mathrm{~mm}$ with a column stub of size $250 \mathrm{~mm} \times 250 \mathrm{~mm} \times 250 \mathrm{~mm}$. Figure 1 shows the measurements of the specimen and the specifies the reinforcement.

The test setup included a steel frame in which the specimens were anchored and hydraulic jacks were used for loading. The upper column is subjected to a vertical load that is dispersed through the column parts. As a result, the specimens may also reflect the negative bending moment region around the interior column, with simply supported edges simulating the line of contra flexure. Tables 1 and 2 show the properties of the concrete and reinforcement used in the high-strength slab-column connections indicated by (H. Marzouk 1993). 

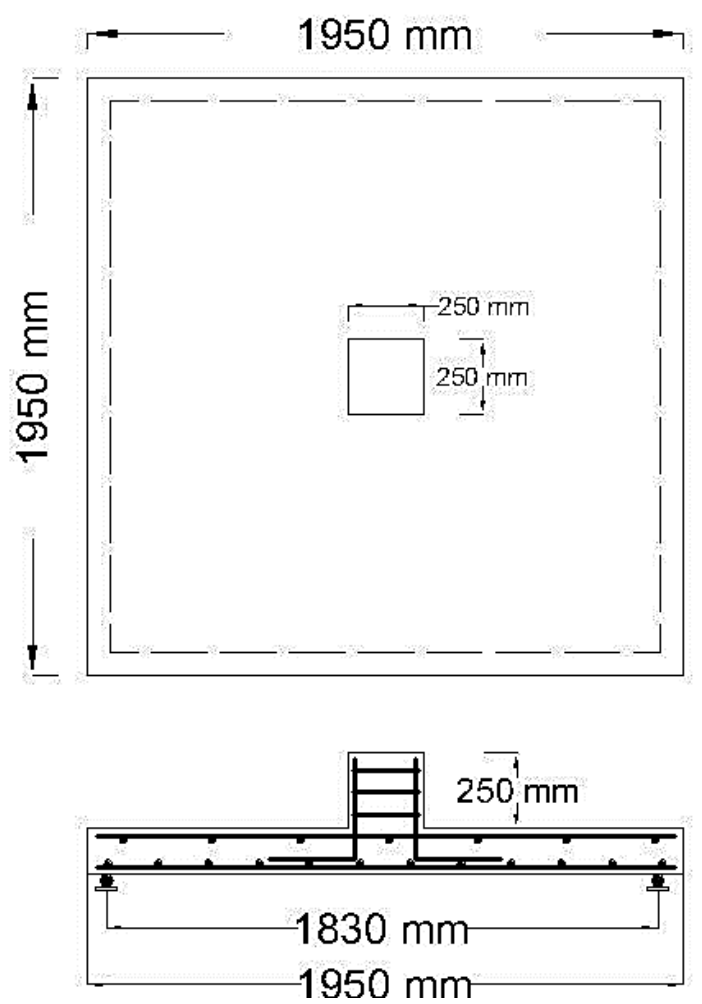

Figure 1. Schematic diagram of simulation model [3]

Table 1. Properties of concrete materials

\begin{tabular}{|c|c|c|c|}
\hline $\begin{array}{c}\text { Study of } \\
\text { slab }\end{array}$ & $\begin{array}{c}\text { Tensile } \\
\text { strength of } \\
\text { concrete } \\
\mathrm{f}^{\prime} \mathrm{t}(\mathrm{MPa})\end{array}$ & $\begin{array}{c}\text { Compressive } \\
\text { strength of } \\
\text { concrete } \mathrm{f}^{\prime} \mathrm{c} \\
(\mathrm{MPa})\end{array}$ & $\begin{array}{c}\text { Yield strength of } \\
\text { flexural } \\
\text { reinforcement fy } \\
(\mathrm{MPa})\end{array}$ \\
\hline HS17 & 4.5 & 67 & 420 \\
\hline
\end{tabular}

Table 2. Flexural reinforcement material properties

\begin{tabular}{|c|c|c|c|c|c|}
\hline Layer & $\begin{array}{c}\text { Bar } \\
\text { Size }\end{array}$ & $\begin{array}{c}\mathrm{f}_{\mathrm{y}} \\
(\mathrm{MPa})\end{array}$ & $\square \mathrm{y}$ & $\begin{array}{c}\mathrm{f}_{\mathrm{t}} \\
(\mathrm{MPa})\end{array}$ & ${ }^{\square y}$ \\
\hline Compressive & $10 \mathrm{M}$ & 496 & 0.002 & 690 & 0.083 \\
\hline Tensile & $15 \mathrm{M}$ & 420 & 0.002 & 600 & 0.115 \\
\hline
\end{tabular}

\section{Finite Element Modeling}

The ABAQUS program is used to perform finite element modelling and nonlinear analysis in this research. The HS17 of a quarter of the slab-column connections was simulated and used as a control specimen for further investigation due to symmetry (H. M. Marzouk \& Chen, 1993). The reinforcement was assigned using 3D two-knot truss (T3D2) elements capable of transmitting vertical load, and the concrete was assigned using eigth-noded linear brick elements with reduced integration (1 integration point) elements (C3D8R). The C3D8R finite elements are reduced-three-dimensional integration (3D) first-order continuous stress/displacement solid elements. Reduced integration was chosen for these components to avoid the shear-locking problem. The Embedded method was considered to be a perfect bond between concrete and reinforcement. However, the use of tension stiffening for tensile behaviour of concrete-reinforcement interaction is only considered and discussed in passing here. Simply supported was used to add boundary conditions to the edge of the slab.

Throughout the depth, the $150 \mathrm{~mm}$ thickness of the slab meshed with five $30 \mathrm{~mm}$ scale brick components. The specimen HS17 had 18376 mesh elements and 21571 nodes. Slab-column specimen supports, provided in experimental steel rollers, were modelled at the bottom edges of the specimens in vertical direction (Z-Direction) constraints, as shown in Figure.2. At the edge of the slab, boundary conditions have been defined, and a reaction force equal to the punching shear load is generated by the sum of the edges of the slab. Vertical displacement was restricted only at the slab's edges (Z-direction in Figure.2) and all other rotational degrees of freedom were permitted.

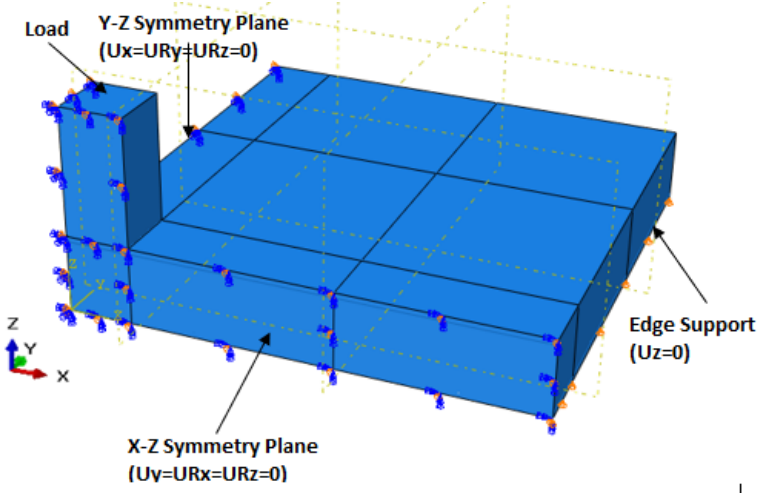

Figure 2. Loading and Boundary condition of the HS17 slab specimen

The Concrete Damage Plasticity model in ABAQUS manual is useful for simulating the action of high-strength concrete. Previous research on modelling techniques for structural concrete using damage plasticity models has been successfully validated with experimental results. Concrete failure mechanisms are believed to be 1) cracking and 2) crushing in the numerical analysis. In this model, (ABAQUS:2014) G considered as Drucker Prager (D-P) plastic yield function is used:

$$
\mathrm{G}=\sqrt{\left(\varepsilon \sigma_{t 0} \tan \psi\right)^{2}+\bar{q}^{2}}-\bar{p} \tan \psi
$$

Where at Eq. (1), $\varepsilon$ is the eccentricity, this determines the rate at which the function reaches the asymptote and default value is 0.1 was used.

The constitutive model for concrete is performed independently at each integration point of the finite element model. Compressive crushing and tensile cracking are the most common failure mechanisms for isotropic materials. Furthermore (Lubliner et al., 1989) the Scalar damage variables are taken into account for the reduction of concrete stiffness, including both 
compression and stress behaviours ( $\mathrm{dc}$ and $\mathrm{dt}$ ). The harm variable's value varies from 0 (undamaged) to 1 (damaged), respectively. For nonlinear behaviour of high-strength concrete, the post-cracking behaviour of concrete is vital important and used for accurate predictions of deflections, crack pattern and shear transfer. The compressive behaviour of high-strength concrete was measured using a cylindrical test to assess the stress-strain behaviour of high-strength concrete. Concrete stressstrain curve relationships can be categorized into three levels based on statistical analysis. The first stage of the curve is the linear elastic branch, which begins at zero and progresses $\boldsymbol{\sigma}_{\mathbf{0}} \boldsymbol{o r} \boldsymbol{E}_{\mathbf{0}}=0.4 f_{c}^{\prime}$. According to (Eurocode2, 2004), the secant stress module $E_{\text {sec }}=22000\left[f_{c m} / 10\right]^{0.3}$ reaches peak stress as the second sector of the curve ascending from linear to plasticity. After hitting the peak tension, the third sector is a decreasing portion that leads to the ultimate strain $\varepsilon_{u}$. According to [3], the ultimate strain recorded by a high-strength concrete slab is 0.0035 , with a poison ratio of 0.24 .

The descending branches of the complete stress-average crack-opening strain diagrams are used to reflect the different values of tension stiffening. The descending branch of stress-strain curve is used equation of (Carreira \& Chu, 1985) for high-strength concrete. It is completely different from the normal strength concrete behaviour. The total area under the complete uniaxial tensile stress-strain curve of high-strength concrete is equal to about the five times the area under the ascending branch of the same curve (Carreira \& Chu, 1985).

In this constitute equation shows good prediction of uniaxial compression stress - high strength concrete strain curves. Figure 3 Shows uniaxial stress -strain curve to implement in FEA at Eq. (2) for stress - strain is given below:

$$
\frac{f_{c}}{f^{\prime} c}=\frac{\beta\left(\frac{\varepsilon}{\varepsilon_{c m}}\right)}{\beta-1+\left(\frac{\varepsilon}{\varepsilon_{c m}}\right)^{\beta c}}
$$

$\beta=$ a material perimeter depending on the stress - strain diagram.

It is governed by

$$
\beta=\frac{1}{1-\left(\frac{f^{\prime} c}{\varepsilon_{0 E_{i t}}}\right)}
$$

$\mathrm{E}_{\mathrm{it}}=$ initial tangent modulus of concrete, can be estimated by (Lee \& Fenves, 1998)

It is given by

$$
\mathrm{E}_{\mathrm{it}}=10200\left(f^{\prime} c\right)^{1 / 3} \text { in Mpa }
$$

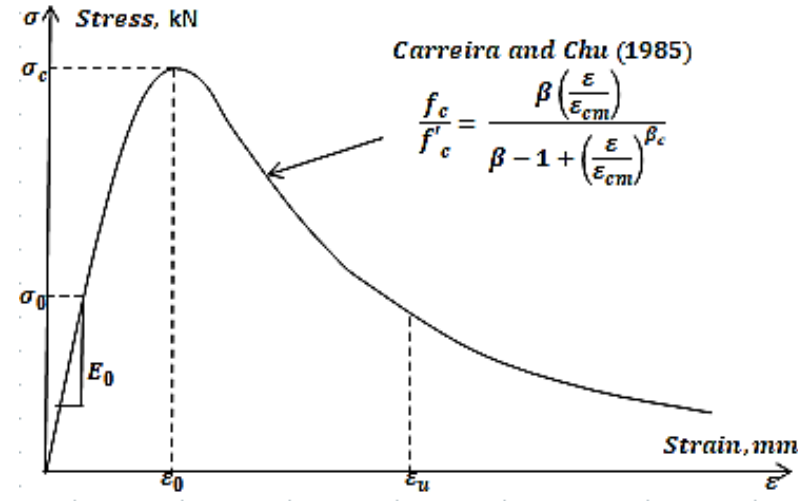

Figure 3. Uniaxial stress - strain curve for FEA

The Quasi-brittle material like concrete, the fracture energy is predicated in the way tension softening curve. The Shear stress transfer between the reinforcement and concrete structures is called Tension softening curve. The bi-linear or Exponential softening relationship curve scored same results and then bi-linear curve is choosing for this work.

The stress-strain relationship of concrete in tension behaviour is linear elastic up to its extent Ultimate tensile strength f't in the bi-linear softening curve (Hillerborg et al., 1976) After cracking, a softening method is used to model the descending branch, which ends at the tensile strain $\varepsilon_{\mathrm{u}}$, where the residual tensile strength is zero in Figure 4. The brittle behaviour of the concrete is often characterized by a stress-crack displacement response rather than a stress - strain relationship. Bilinear stiffening response was used in this study, $\mathrm{f}^{\prime} \mathrm{t}=2.12 \ln [1+(\mathrm{fcm} / 10)]$ as per (Eurocode2, 2004) where f't is the maximum tensile strength and Gf denotes the concrete fracture energy that represents the area under the tensile stress-crack displacement curve.

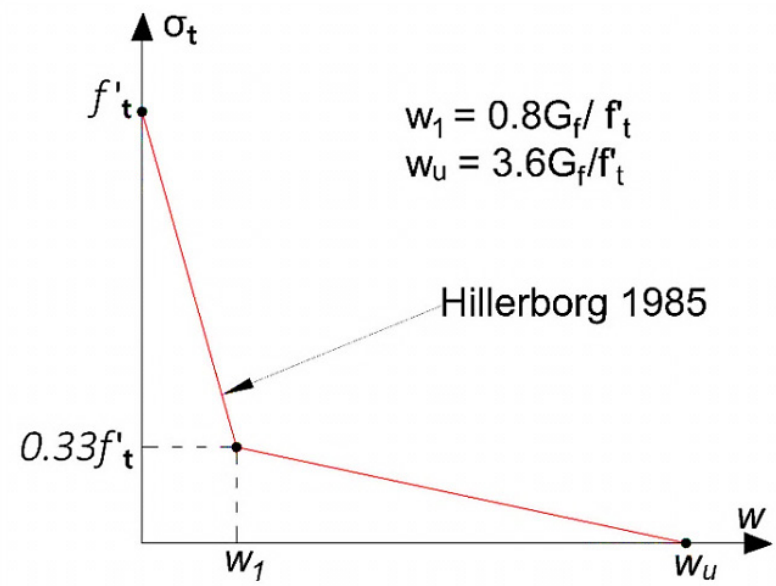

Figure 4. Uniaxial concrete Tensile stress - crack displacement for FEA 
Fracture energy Gf can be calculated using the expression $\mathrm{Gf}=\mathrm{GfO}(0.1 \mathrm{fcm}) 0.7$ in accordance with the CEB-FIB (1993), where Gf0 is the fracture energy base value based on the maximum aggregate size used in the concrete mixture and fcm expressed in MPa. The value of Gf0 equals a maximum aggregate size of $10 \mathrm{~mm}$, equal to $0.026 \mathrm{~N} / \mathrm{mm}$.

According to (Eurocode2, 2004), fcm is concrete's mean compressive strength and its relationship to the characteristic value, $\mathrm{f}_{\mathrm{ck}}$, is:

$$
\mathrm{f}_{\mathrm{cm}}=\mathrm{f}_{\mathrm{ck}}+8 \text { in Mpa }
$$

Damage in tension dt and compression dc have been implemented in concrete damaged plasticity model to describe the degradation of the elastic stiffness. The Compression damage was performed after the peak load corresponding to the $\varepsilon_{0}$ strain point had been reached. The magnitude of the strain observed at peak stress $\varepsilon_{0}$ (Wee et al., 1996),

$$
\varepsilon_{0}=0.00078\left(\mathrm{f}_{\mathrm{c}}\right)^{1 / 4}
$$

\section{Design Provisions}

In Canadian (CAN/CSA-A23.3-04, 2004) and Eurocode2 (2004), the estimation of the punching shear is based on the critical perimeter and the concrete compressive strength $\left(\mathrm{f}^{\prime} \mathrm{c}\right)$. According to the Canadian and Euro code, the critical perimeter is $0.5 \mathrm{~d}$ and $2 \mathrm{~d}$ (i.e. $\mathrm{d}$ is effective slab depth) respectively. The predicted punching shear strength of slab was calculated on the basis of the critical perimeter and compared to the FEA results.

\subsection{Canadian Standard (CAN/CSA-A23.3-04-2004):}

The Ultimate Punching shear strength $V_{u}$ is given in (6).

$$
V_{u}=\min .\left\{\begin{array}{c}
0.19 \lambda\left(1+2 / \beta_{c}\right) \sqrt{f_{c}^{\prime}} \\
\lambda\left(\alpha_{s} d / u+0.19\right) \sqrt{f_{c}^{\prime}} \\
0.38 \lambda \sqrt{f_{c}^{\prime}}
\end{array}\right.
$$

Where, $\boldsymbol{\lambda}$ is a low-density concrete factor equal to 1.0 , $0.85,0.75$ (Normal Concrete), $\beta_{c}$ is the ratio of the long to short sides of the cross-section column, $\alpha_{s}$ is the value of 40 (Inner column), 30 (Edge column) and 20 (corner column) respectively, $f_{c}^{\prime}$ is the compressive strength of the cylindrical concrete in MPa.
The Ultimate feature strength is determined according to (CAN/CSA-A23.3-04-2004) as,

$$
V_{c d}=\emptyset_{c} V_{u}
$$

Where $\emptyset_{c}=0.85$ where the resistance is concrete factor

\subsection{EC:2 (Eurocode:2-2004):}

The Ultimate shear strength of concrete is determined by

$$
v_{R d, c}=0.18 k b_{0} d\left(100 \rho_{\text {ave }} f_{c k}\right)^{1 / 3} \geq v_{c . m i n}
$$

Where $b_{0}$ is the control perimeter at a distance $2 \mathrm{~d}$ from the column, $\mathrm{d}$ is the slab's effective depth, $f_{c k}$ is the concrete's compressive strength feature, $\rho_{\text {ave }}$ is the maximum value of 0.02 and $\mathrm{k}$ is the size impact factor.

$$
\begin{gathered}
\rho_{\text {ave }}=\left(\rho_{x} \rho_{y}\right)^{0.5} \leq 0.02 \\
\mathrm{k}=1+\sqrt{\frac{200}{d}} \leq 2.0 \quad(\text { d in } \mathrm{mm}) . \\
v_{\text {c.min }}=0.035(k)^{3 / 2}\left(f_{c k}\right)^{0.5} b_{0} d
\end{gathered}
$$

Because $f_{c}^{\prime}$ represents 9 percent, and $f_{c k}$ represents the 5 percent average concrete compressive strength, $f_{c}^{\prime}$ to $f_{c k}$.

$$
f_{c k}=f_{c}^{\prime}-1.60 \mathrm{MPa} .
$$

\section{Punching Shear Strength of Control Slab}

\subsection{Comparison of Finite Element Analysis with Code Prediction}

To prove the validity of the finite element model, the results computed by finite element analysis are compared to the results of the existing test in Table 3. For this reason, the variations of maximum deflections of the interior slab-column connections versus applied ultimate load are depicted in Figure 5 respectively; and the results of displacements are computed by finite element modelling

\begin{tabular}{|c|c|c|c|c|c|c|c|}
\hline \multirow{2}{*}{ Specimen } & \multicolumn{2}{|c|}{ Experiment } & \multicolumn{2}{|c|}{ FEA Analysis } & \multirow{2}{*}{$\mathrm{Q}_{\mathrm{u} \text { FEA }} / \mathrm{Q}_{\mathrm{u} \text { TEST }}$} & \multicolumn{2}{|c|}{$\mathrm{V}_{\text {test }} / \mathrm{V}_{\text {pred }}$} \\
\hline & $\mathrm{Q}_{\mathrm{u}}, \mathrm{kN}$ & $\Delta_{\boldsymbol{u}} \mathrm{mm}$ & $\mathrm{Q}_{\mathrm{u}}, \mathrm{kN}$ & $\Delta_{\boldsymbol{u}} \mathrm{mm}$ & & $\mathrm{EC} 2$ & CSA \\
\hline HS17 & 127.77 & 23.43 & 125.05 & 24.20 & 0.979 & 0.933 & 1.031 \\
\hline
\end{tabular}
are compared with the corresponding experimental results by H.M. Marzouk. Finally, it is concluded that the approach adopted for nonlinear analysis is capable to predict the slab's behaviour under applied loads. According to the experimental results, the brittle punching shear failure was reported for the slab-column connections; the same failure mode was observed in the FE model.

Table 3. Model predictions compared with experimental results 


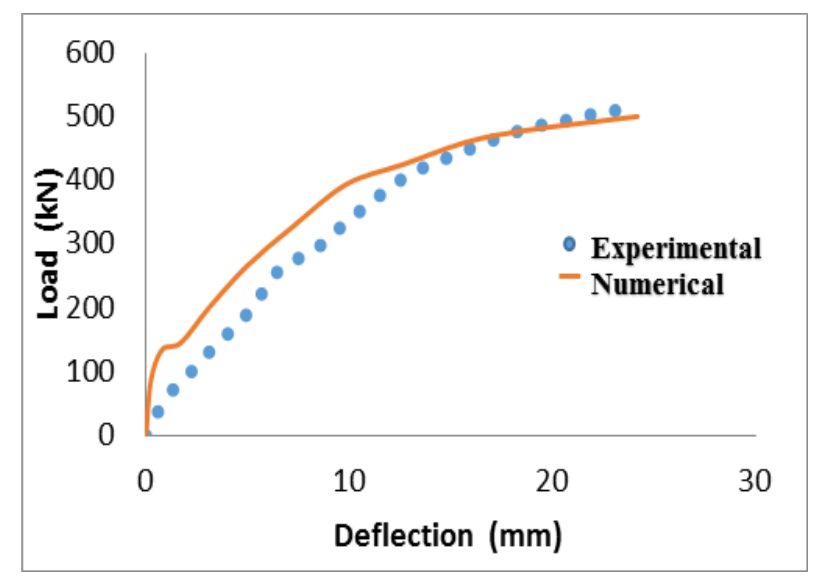

Figure 5. Load-deflection response of HS17

\subsection{Crack Generation}

The generation of cracking for the control specimen HS17 is observed at the ultimate failure. In FEA, the plastic tensile equivalent strain (PEEQT) and the maximum plastic strain (PE Max. Principal) are thought to be positive and greater than zero (Abaqus Manual). Crack generation is radially distributed across the column on the tension side of the slab. Figure 6. depicts the tension side cracking generation in the slab-column HS17 specimen.

\section{Parametric Investigation - Effect of Opening Location and Size}

To construct and consider it as a reference slab, the model given in the computed HS17 NLFEA is used. The size and location of the openings given in the high-strength slab-column specimen are established in this parametric investigation. Figure 7: Schematic diagrams for various sizes and positions of openings. In the reference slab HS17, the square and rectangle openings are discussed. A total of 42 slabs are analysed, with flexural reinforcement in the openings removed and equivalent reinforcement applied around the opening and the amount of the reinforcement ratio was the same as it was without openings. Results are compared with the codal predictions and plotted as shown in Figure 8. From the plot it is clear that Eurocode is well in agreement with the FEA results. Figure 9 depicts the crack pattern on the bottom surface of selected slabs at ultimate load for the different opening sizes. The maximum principal plastic strain (PE) can be used to demonstrate cracking in the damaged plasticity model of concrete. From the plastic strain output, we can understand that $60 \mathrm{~mm}$ X $60 \mathrm{~mm}$ and $60 \mathrm{~mm}$ X120 mm openings irrespective of the location, slab behaves uniformly. But other opening sizes having little impact on the slab due to different location.

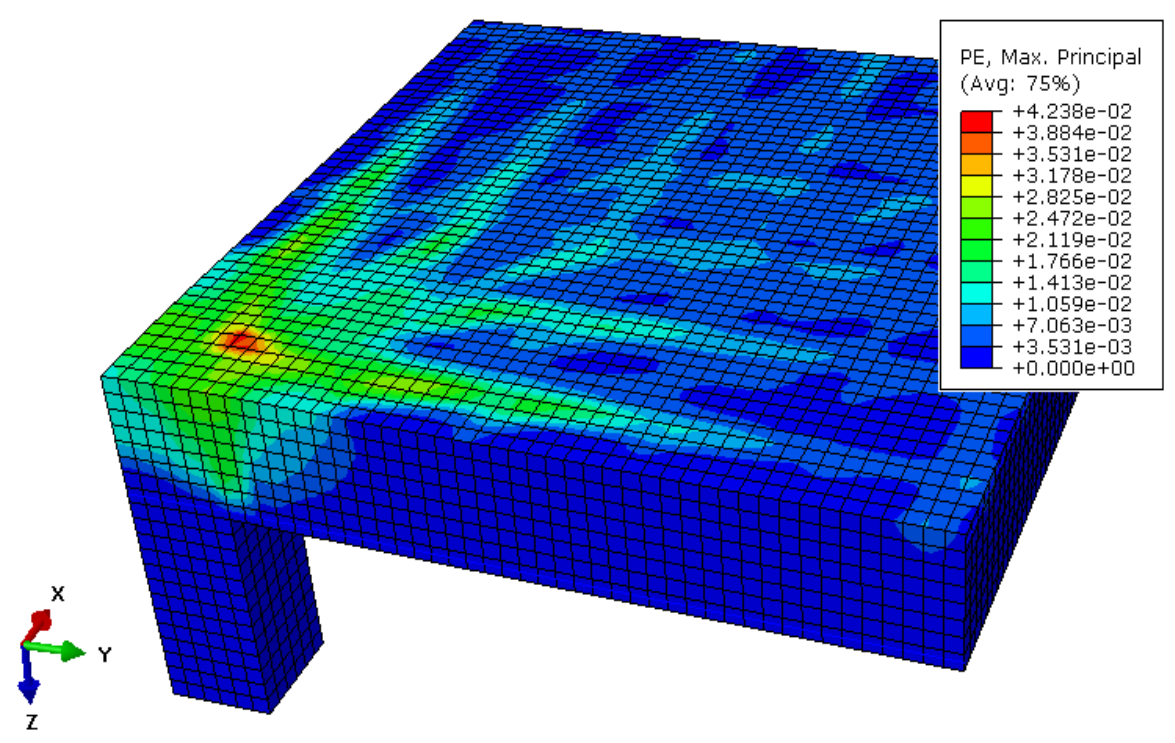

Figure 6. Crack Formation of Control Specimen HS17 (Tension Surface) 


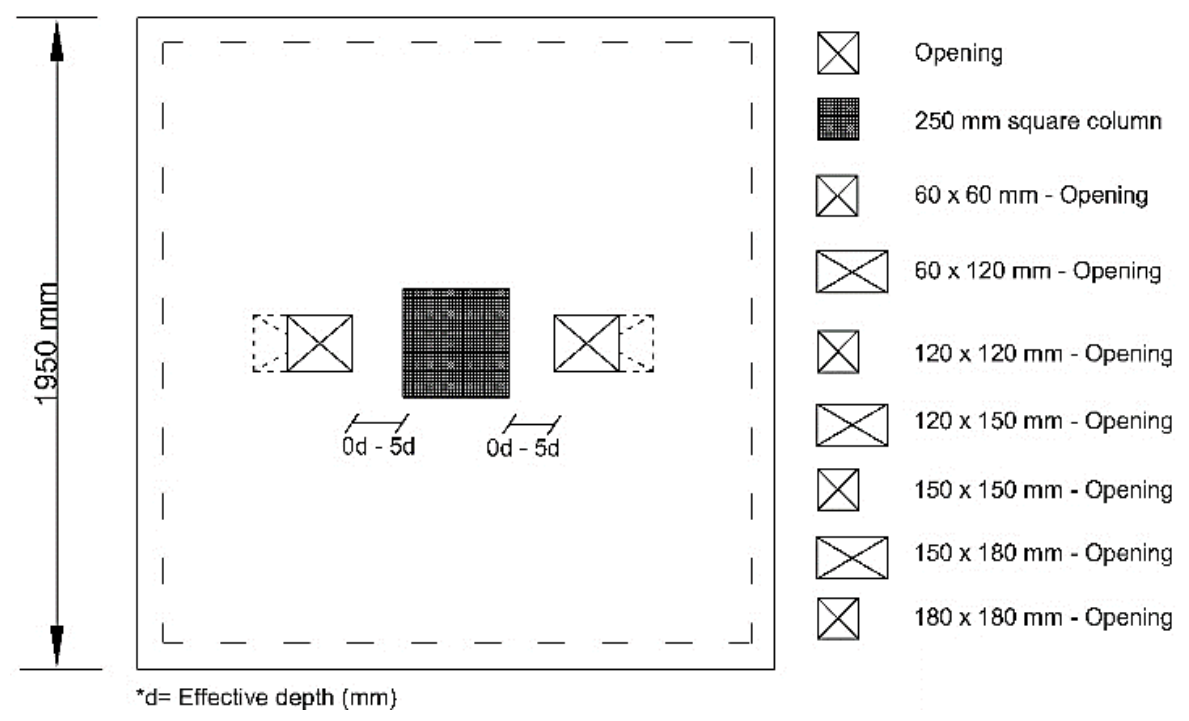

Figure 7. Schematic diagram for openings size and location from the column in HS17 Specimen

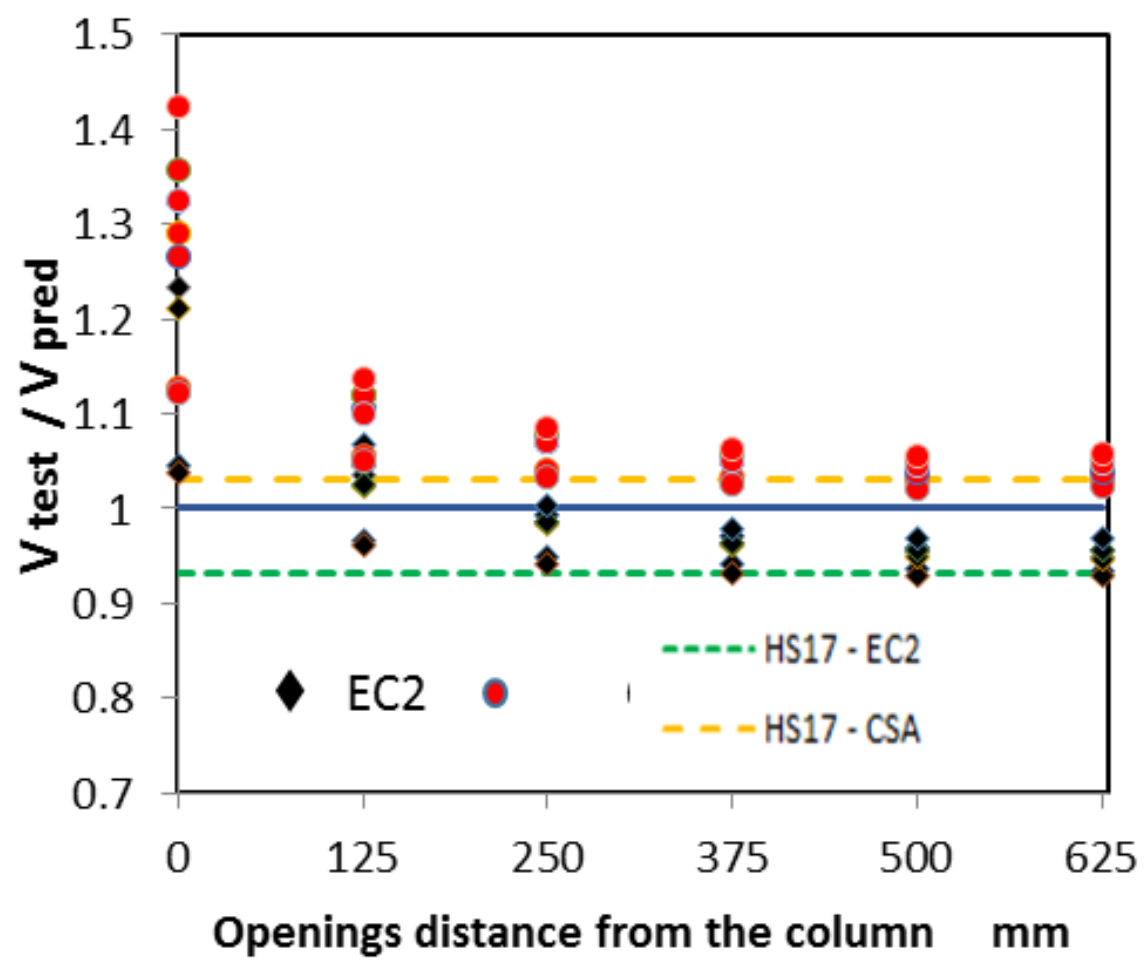

Figure 8. Codal Prediction

The effect of openings in different locations on punching shear strength was studied in this analysis. The punching shear strength of various slabs with different opening locations is tabulated in Table 4 . The openings 60 $\mathrm{mm}$ X $60 \mathrm{~mm}, 60 \mathrm{~mm} \mathrm{X120} \mathrm{mm} \mathrm{and} 120 \mathrm{~mm}$ X $120 \mathrm{~mm}$ size have little effect up to $2 \mathrm{~d}$ distance, beyond that no effect on the strength. Other opening sizes have notable effect up to $2 \mathrm{~d}$ distance beyond which only negligible amount. The maximum reduction in strength was absorbed in $180 \mathrm{~mm}$ X180 mm size opening at 0d. From this we can conclude that suggested openings can be provided from 1d onwards. According to the codal predictions, both Eurocode and Canadian standard overestimate the punching shear strength of all the openings at $0 \mathrm{~d}$ but for other locations well agreed with FEA results. 
Table 4. Comparison between CSA and EC2 codes vs FEA results

\begin{tabular}{|c|c|c|c|c|c|c|c|}
\hline \multirow{2}{*}{ S.NO. } & \multirow{2}{*}{ Specimen } & \multirow{2}{*}{$\begin{array}{c}\text { Opening } \\
\text { Dimension }\end{array}$} & \multirow{2}{*}{$\begin{array}{l}\text { Opening } \\
\text { distance }\end{array}$} & \multirow{2}{*}{$\begin{array}{c}\text { Punching } \\
\text { Shear } \\
\text { Strength }(\mathrm{kN}) \\
\end{array}$} & \multirow{2}{*}{$\begin{array}{c}\text { Percentage } \\
\text { reduction in } \\
\text { shear strength }\end{array}$} & \multicolumn{2}{|c|}{$\mathrm{V}_{\mathrm{FEA}} / \mathrm{V}_{\text {Pred }}$} \\
\hline & & & & & & $\mathrm{EC} 2$ & CSA A23.13- 04 \\
\hline 1 & HSO-1 & $60 \times 60$ & \multirow{7}{*}{$0 \mathrm{~d}$} & 492 & 1.6 & 1.044 & 1.13 \\
\hline 2 & HSO-2 & $60 \times 120$ & & 489 & 2.2 & 1.038 & 1.12 \\
\hline 3 & HSO-3 & $120 \times 120$ & & 486 & 2.8 & 1.232 & 1.3 \\
\hline 4 & HSO-4 & $120 \times 150$ & & 477 & 4.6 & 1.209 & 1.3 \\
\hline 5 & HSO-5 & $150 \times 150$ & & 471 & 5.8 & 1.323 & 1.36 \\
\hline 6 & HS0-6 & $150 \times 180$ & & 460 & 8 & 1.292 & 1.33 \\
\hline 7 & HSO-7 & $180 \times 180$ & & 452 & 9.6 & 1.423 & 1.42 \\
\hline 8 & HS1-1 & $60 \times 60$ & \multirow{7}{*}{$1 d$} & 492 & 1.6 & 0.966 & 1.05 \\
\hline 9 & HS1-2 & $60 \times 120$ & & 490 & 2 & 0.9621 & 1.05 \\
\hline 10 & HS1-3 & $120 \times 120$ & & 488 & 2.4 & 1.036 & 1.12 \\
\hline 11 & HS1-4 & $120 \times 150$ & & 482 & 3.6 & 1.023 & 1.10 \\
\hline 12 & HS1-5 & $150 \times 150$ & & 472 & 5.6 & 1.044 & 1.12 \\
\hline 13 & HS1-6 & $150 \times 180$ & & 463 & 7.4 & 1.024 & 1.1 \\
\hline 14 & HS1-7 & $180 \times 180$ & & 462 & 7.6 & 1.068 & 1.14 \\
\hline 15 & HS2-1 & $60 \times 60$ & \multirow{7}{*}{$2 d$} & 495 & 1 & 0.948 & 1.04 \\
\hline 16 & HS2-2 & $60 \times 120$ & & 492 & 1.6 & 0.942 & 1.03 \\
\hline 17 & HS2-3 & $120 \times 120$ & & 490 & 2 & 0.986 & 1.07 \\
\hline 18 & HS2-4 & $120 \times 150$ & & 488 & 2.4 & 0.982 & 1.07 \\
\hline 19 & HS2-5 & $150 \times 150$ & & 481 & 3.8 & 0.994 & 1.08 \\
\hline 20 & HS2-6 & $150 \times 180$ & & 477 & 4.6 & 0.986 & 1.09 \\
\hline 21 & HS2-7 & $180 \times 180$ & & 473 & 5.4 & 1.004 & 1.08 \\
\hline 22 & HS3-1 & $60 \times 60$ & \multirow{7}{*}{$3 d$} & 497 & 0.6 & 0.94 & 1.03 \\
\hline 23 & HS3-2 & $60 \times 120$ & & 493 & 1.4 & 0.932 & 1.02 \\
\hline 24 & HS3-3 & $120 \times 120$ & & 491 & 1.8 & 0.964 & 1.05 \\
\hline 25 & HS3-4 & $120 \times 150$ & & 490 & 2 & 0.962 & 1.05 \\
\hline 26 & HS3-5 & $150 \times 150$ & & 485 & 3 & 0.97 & 1.06 \\
\hline 27 & HS3-6 & $150 \times 180$ & & 482 & 3.6 & 0.964 & 1.05 \\
\hline 28 & HS3-7 & $180 \times 180$ & & 480 & 4 & 0.979 & 1.06 \\
\hline 29 & HS4-1 & $60 \times 60$ & \multirow{7}{*}{$4 d$} & 499 & 0.2 & 0.937 & 1.03 \\
\hline 30 & HS4-2 & $60 \times 120$ & & 494 & 1.2 & 0.928 & 1.02 \\
\hline 31 & HS4-3 & $120 \times 120$ & & 493 & 1.4 & 0.953 & 1.04 \\
\hline 32 & HS4-4 & $120 \times 150$ & & 490 & 2 & 0.947 & 1.04 \\
\hline 33 & HS4-5 & $150 \times 150$ & & 488 & 2.4 & 0.958 & 1.05 \\
\hline 34 & HS4-6 & $150 \times 180$ & & 487 & 2.6 & 0.956 & 1.05 \\
\hline 35 & HS4-7 & $180 \times 180$ & & 486 & 2.8 & 0.968 & 1.06 \\
\hline 36 & HS5-1 & $60 \times 60$ & \multirow{7}{*}{$5 \mathrm{~d}$} & 500 & 0 & 0.934 & 1.03 \\
\hline 37 & HS5-2 & $60 \times 120$ & & 497 & 0.6 & 0.929 & 1.02 \\
\hline 38 & HS5-3 & $120 \times 120$ & & 496 & 0.8 & 0.95 & 1.04 \\
\hline 39 & HS5-4 & $120 \times 150$ & & 494 & 1.2 & 0.946 & 1.04 \\
\hline 40 & HS5-5 & $150 \times 150$ & & 493 & 1.4 & 0.956 & 1.05 \\
\hline 41 & HS5-6 & $150 \times 180$ & & 493 & 1.4 & 0.956 & 1.05 \\
\hline 42 & HS5-7 & $180 \times 180$ & & 491 & 1.8 & 0.968 & 1.06 \\
\hline
\end{tabular}


$0 \mathrm{~d}$
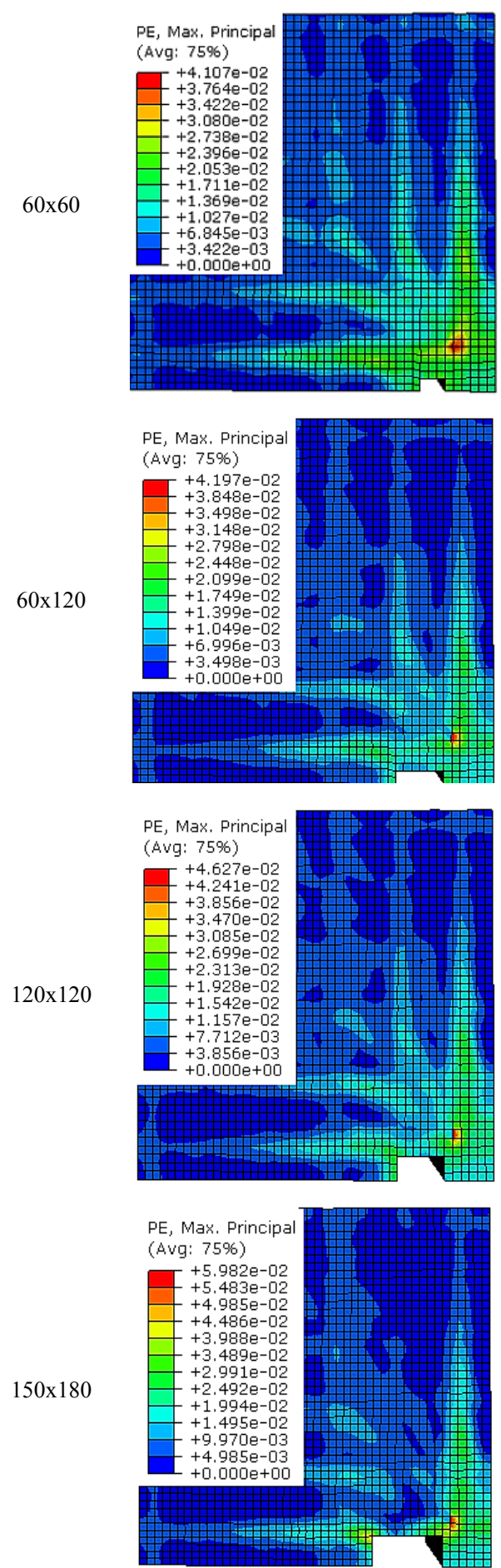

$3 d$
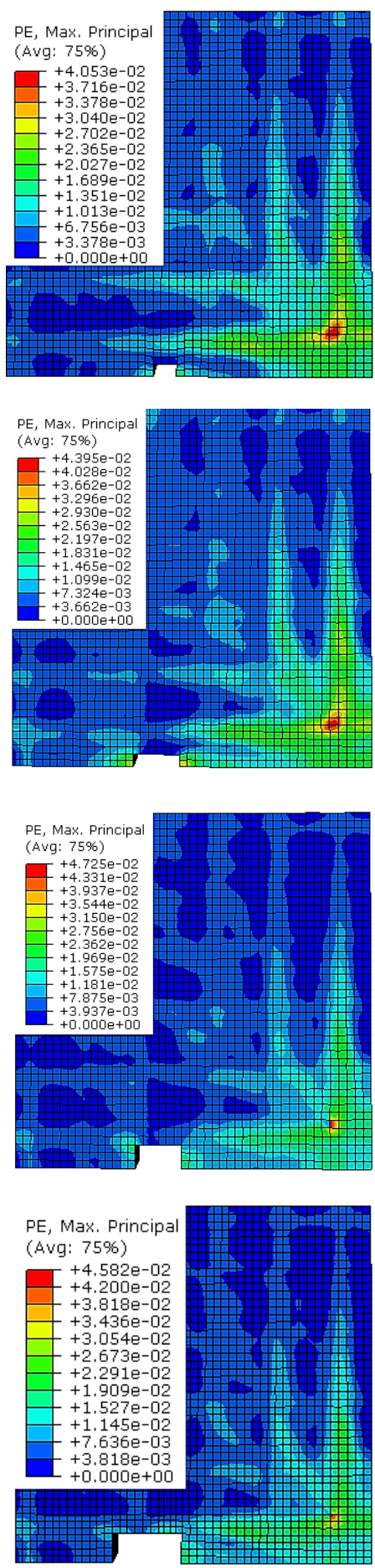

$4 d$
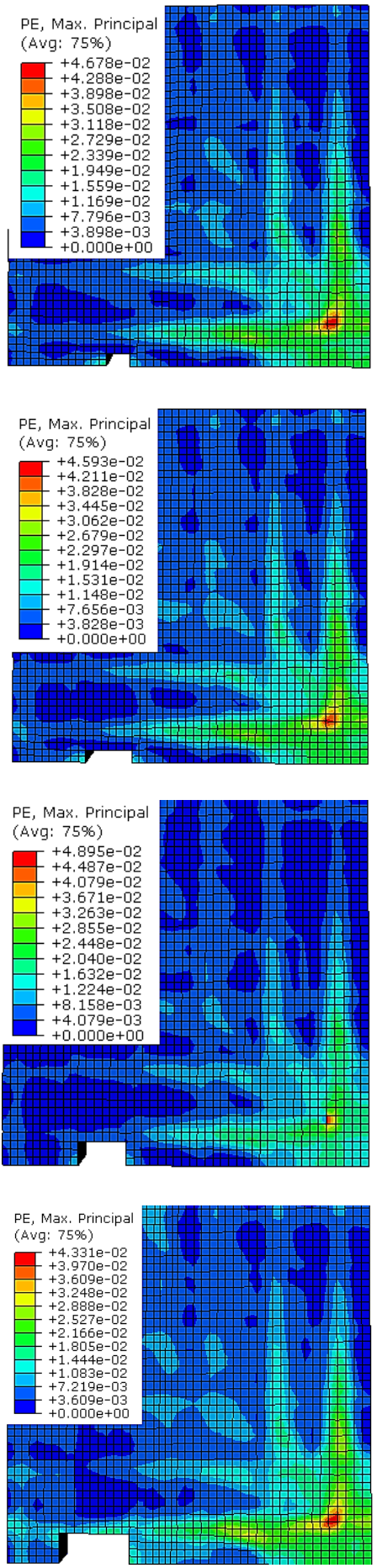

Figure 9. Crack pattern for high-strength interior slab-column connections with openings

\section{Conclusions}

In this study, the punching shear response of slabs without shear reinforcement was predicted using a finite element analysis. The constitutive formulation used in this study is a damaged plasticity model implemented in ABAQUS, a finite element program. The experimental results of the HS17 slabs were used to calibrate the constitutive model. When the results of the analysis were compared with the results of the test, they showed a high degree of agreement.

The results of the finite element study support the ability of the proposed model to predict punching shear failure in concrete slab. Finite element analysis is useful 
as a method for assessing punching shear failure and crack formation, since it allows for parametric studies that cannot be obtained from experimental investigations.

Overall, the shear capacity of the connection was reduced to the maximum of 9.6 percent due to the opening position adjacent to the column. The punching shear capacity is slightly reduced when the opening located beyond $2 \mathrm{~d}$ distance. However, considering the openings in the critical zone $0 \mathrm{~d}$ to $2 \mathrm{~d}$, the improvisation required for future investigation.

The capacity of the slab is influenced by the size of the opening. Based on the size of the column, the final strength of the slab with wide openings $(180 \mathrm{~mm} \mathrm{X} 180$ $\mathrm{mm}$ ) is reduced. The shear capacity of the slab-column is not affected by the shape of the opening (square or rectangle).

The punching shear resistance in the Eurocode 2 is proportional to the reinforcement ratio and the cubic root of the concrete compressive strength, allowing for better calculations of HSC punching shear resistance. The punching shear resistance of Canadian standards is proportional to the square root of the concrete shear stresses resulting in an overestimation of HSC punching shear resistance.

\section{REFERRENCES}

[1] J. Moe, "Shearing Strength of Reinforced Concrete Slabs and Footings under concentrated loads," 1961. doi: 10.1007/s00466-012-0717-7.

[2] H. Marzouk and A. Hussein, "Experimental investigation on the behaviour of high-strength concrete slabs," $A C I$ Struct. J., vol. 88, no. 6, pp. 701-713, 1991, doi: $10.14359 / 1261$.

[3] H. M. Marzouk and Z. Chen, "Finite Element Analysis Of High-Strength Concrete Slabs," ACI Struct. J., vol. 90, no. 5, pp. 505-513, 1993.

[4] K. Ramdane, "Punching Shear of High-Performance Concrete Slabs," in Proceedings of the 4th International Symposium on Utilization of High Strength High Performance Concrete,Paris, 1996, pp. 1015-1026, doi: 10.1080/19648189.2019.1578270.

[5] H. Marzouk, M. Emam, and M. Sameh Hilal, "Effect of high-strength concrete columns on the behaviour of slab-column connections," ACI Struct. J., vol. 93, no. 5, pp. 545-554, 1996.

[6] H. Marzouk, M. Emam, and M. S. Hilal, "Effect of High-Strength Concrete Slab on the Behaviour of Slab-Column Connections," ACI Struct. J., vol. 95, no. 3, pp. 227-236, 1999.

[7] A. Hussein and H. Marzouk, "Finite element evaluation of the boundary conditions for biaxial testing of high strength concrete," Mater. Struct. Constr., vol. 33, no. 229, pp. 299
308, 2000, doi: 10.1007/bf02479700.

[8] A. Hillerborg, "Analysis of one single crack, fracture mechanics of concrete.," Amsterdam, Netherland: Elseiver, pp. 223-249, 1983.

[9] J. Mazars, "A description of micro- and macroscale damage of concrete structures," Eng. Fract. Mech., vol. 25, no. 5-6, pp. 729-737, 1986, doi: 10.1016/0013-7944(86)90036-6.

[10] A. Hillerborg, "The Compression stress-strain curve for design of reinforced concrete beams, Fracture Mechanics: Application to Concrete," Detroit, Michigan, p. 118, 1989.

[11] J. Lubliner, J. Oliver, S. Oller, and E. Onate, "A Plastic-Damage Model for Concrete," Int. J. Solids Struct., vol. 25, no. 3, pp. 299-326, 1989.

[12] P. . Feenstra and R. De Borst, "Constitutive Model for Reinforced Concrete," 1Journal Eng. Mech., vol. 121, no. 5, pp. 587-595, 1995, doi: 10.1061/(ASCE)0733-9399(1995) 121.

[13] J. Lee and G. L. Fenves, "Plastic-damage model for cyclic loading of concrete structures," J. Eng. Mech., vol. 124, no. 8, pp. 892-900, 1998, doi: 10.1061/(ASCE)0733-9399(199 8)124:8(892).

[14] R. Malm, "Shear cracks in concrete structures subjected to in-plane stresses," 2006.

[15] ABAQUS, Analysis User's Manual 6.14. 2014.

[16] Eurocode2, Design of Concrete Structures - Part 1-1. General Rules and Rules for buildings. 2004.

[17] CAN/CSA-A23.3-04, "A national standard of Canada: Design of concrete structures," 2004, p. 258.

[18] D. J. Carreira and K.-H. Chu, "Stress-Strain Relationship for Plain Concrete in Compression," $A C I J$., no. 82, pp. 797-804, 1985, doi: 10.1007/BF02473452.

[19] T. H. Wee, M. S. Chin, and M. A. Mansur, "Stress-strain relationship of high-strength fiber concrete in compression," J. Mater. Civ. Eng., vol. 8, no. 2, pp. 70-76, 1996, doi: 10.1061/(ASCE)0899-1561(1999)11:1(21).

[20] A. Hillerborg, M. Modeel, and P. E. Petersson, "Analysis of crack formation and crack growth in concrete by means of fracture mechanics and finite elements," Cem. Concr. Res., vol. 6, no. 6, pp. 773-782, 1976, doi: 10.1016/j.ijmecsci.2018.09.046.

[21] M. M. G. Inácio, M. Lapi, and A. Pinho Ramos, "Punching of reinforced concrete flat slabs - Rational use of high strength concrete," Eng. Struct., vol. 206, no. January, p. 110194, 2020, doi: 10.1016/j.engstruct.2020.110194.

[22] Y. Han, J. Zhang, Y. Luosun, and T. Hao, "Effect of internal curing on internal relative humidity and shrinkage of high strength concrete slabs," Constr. Build. Mater., vol. 61, pp. 41-49, 2014, doi: 10.1016/j.conbuildmat.2014.02.060.

[23] M. M. Smadi and I. S. Bani Yasin, "Behaviour of high-strength fibrous concrete slab-column connections under gravity and lateral loads," Constr. Build. Mater., vol. 22, no. 8, pp. 1863-1873, 2008, doi: 10.1016/j.conbuildmat.2007.04.023. 